Ind. J. Chem. Res, 2013, 1, 1 - 6

\title{
ANALISIS KADAR SIANIDA PADA REBUNG BERDASARKAN VOLUME UKURAN DARI KECAMATAN BAJENG KABUPATEN GOWA
}

\author{
Analysis of Sianida Contents on Bamboo Shoot Based on The Size Volume From Bajeng \\ Sub-District, District of Gowa
}

\author{
Dewi Arisanti", Nur Qadri Rasyid, Muh.Nasir \\ Study Program of Health Analyst, Academy of Health Analyst Muhammadiyah Makassar-Indonesia \\ *Corresponding author,e-mail: dewiharimuswarah@gmail.com
}

Received: April 2018 Published: July 2018

\begin{abstract}
Bamboo shoots are young shoots from bamboo shoots. Bamboo shoots contain cyanide content if consumed can cause shortness of breath, decreased blood pressure, rapid pulse, headache, nausea, diarrhea, mental disorders and seizures. Continuous consumption with low doses causes mumps and dwarfism and neurological diseases. This study aims to determine how much cyanide levels in bamboo shoots and this type of research is a descriptive laboratory experiment. The sample that used in this study is 3 samples based on the size of the volume. The sampling technique is by means of purposive sampling that is looking at the criteria based on large, medium and small size types. Analysis of cyanide levels was obtained by UV-Vis Spectrophotometer with a wavelength of $582 \mathrm{~nm}$. The results showed that large size bamboo shoots were height $=27 \mathrm{~cm} ;$ diameter $=16 \mathrm{~cm}$ has a cyanide content of $21.84 \mathrm{mg} / \mathrm{Kg}$, medium size were height $=18 \mathrm{~cm}$; diameter $=7 \mathrm{~cm}$ has a cyanide content of $18.40 \mathrm{mg} / \mathrm{Kg}$ and a small size of height $=8 \mathrm{~cm}$; diameter $=4 \mathrm{~cm}$ has cyanide content of $4.65 \mathrm{mg} / \mathrm{Kg}$. Thus it can be concluded that the greater the size of bamboo shoots, the greater the level of cyanide.
\end{abstract}

Keywords: Analysis, bamboo shoot, cianida, spektrofotometer UV-Vis

\section{PENDAHULUAN}

Indonesia merupakan negara yang kaya akan sumber daya alam dengan kesuburan tanah yang luar biasa. Semua kekayaan alam yang ada di Indonesia memiliki banyak kegunaan dan manfaat oleh setiap manusia. Misalnya rebung bambu yang telah membudaya sebagai salah satu bahan masakan tradisional yang cukup popular di masyarakat (Kencana dkk., 2009).

Rebung mengandung nilai gizi yang cukup baik dimana setiap 100 gr rebung mengandung, $27 \mathrm{kkal}$ energi, 2.6 gr protein, 0.3 gr lemak, 5.2 gr karbohidrat, $13 \mathrm{mg}$ kalsium, $59 \mathrm{mg}$ fosfor, 0.5 $\mathrm{mg}$ besi, 20 SI vitamin A, $0.15 \mathrm{mg}$ vitamin B1 dan $4 \mathrm{mg}$ vitamin $\mathrm{C}$, dan merupakan makanan yang kaya serat dan sumber kalium yang baik sehingga dapat menurunkan kolesterol darah serta resiko penyakit kardiovaskuler. Namun, dari beberapa manfaat dari rebung terdapat kandungan asam sianida yang tidak diketahui masyarakat umum. Kandungan sianida yang terdapat pada rebung berpengaruh pada volume ukuran dan lamanya usia rebung tersebut.
Semakin tua rebung maka akan terasa pahit dan kadar sianidanya semakin tinggi. Rebung bambu mengandung asam sianida sekitar $245 \mathrm{mg} / 100 \mathrm{~g}$ dan bervariasi tergantung pada jenis bambunya (Kencana dkk., 2012).

Asam sianida merupakan senyawa yang berbahaya baik bagi manusia maupun hewan. Fsanz (2005) menyatakan dosis letal asam sianida pada manusia dilaporkan $0.5-3.5 \mathrm{mg} / \mathrm{Kg}$ berat badan. Gejala keracunan akut asam sianida pada manusia meliputi: nafas tersengal, penurunan tekanan darah, denyut nadi cepat, sakit kepala, sakit perut, mual, diare, pusing, kekacauan mental dan kejang. mengkonsumsi terus menerus dalam dosis yang rendah menyebabkan berbagai penyakit seperti penyakit gondok, kekerdilan serta penyakit neurologis (Bradbury dan Holloway, 1988).

Cara pengolahan rebung yang baik agar dapat mengurangi sianida yaitu dicuci pada air yang mengalir, dilakukan pengupasan menggunakan pisau stainless, perendaman dengan air garam, pemotongan secara halus, dan perebusan kurang lebih 30 menit serta jika belum 
ingin dimasak, alangkah baiknya disimpan pada lemari es agar kualitas rebung terjaga.

Penelitian ini bertujuan untuk mengetahui kandungan kadar sianida yang terdapat pada rebung pada kondisi mentah berdasarkan volume ukuran (kecil, sedang dan besar). Penelitian ini dapat memberikan informasi kepada masyarakat tentang bagaimana cara mengolah bahan makanan yang baik agar kesehatan masyarakat dapat terjaga.

\section{METODOLOGI}

\section{Bahan}

Bahan yang digunakan adalah sampel rebung, larutan $\mathrm{KCN}$, larutan $\mathrm{AgNO}_{3} 0,1 \mathrm{M}$, $\mathrm{NaCl}$, rhodamin, larutan indikator $\mathrm{K}_{2} \mathrm{CrO}_{4} 5 \%$, larutan $\mathrm{NaOH} 2 \%$, larutan ammonium amidosulfat 10\%, larutan EDTA, Asam fosfat $\mathrm{H}_{2} \mathrm{PO}_{4}$ Asam asetat pekat $(1+8)$, larutan indikator fenolftalein $0,5 \%$, larutan kalium di-hidrogen fosfat $20 \%$, larutan baku fosfat $\mathrm{pH} 7,2$, larutan kloramin- $\mathrm{T}$, larutan $\mathrm{HCl}(1+10)$, larutan 4-piridin asam karboksilat-pirazolon/ asam barbiturat handscoon, masker, dan akuades.

\section{Alat}

Alat yang digunakan adalah pisau, ember, blender, labu ukur $50 \mathrm{ml}, 100 \mathrm{ml}, 250 \mathrm{ml}, 1000$ $\mathrm{ml}$, timbangan analitik, gelas ukur $100 \mathrm{ml}$, alat destilasi, alat spektrofotometer UV-Vis

\section{Prosedur Kerja \\ Pengambilan Sampel}

Sampel penelitian diambil secara langsung dari lahan warga di Kecamatan Bajeng Kabupaten Gowa. Sampel diambil dengan kriteria berdasarkan kriteria ukurannya (Yuningsih, 2008)

1. Sampel A = Sampel rebung yang diambil dengan volume ukuran kecil (dengan diameter kurang lebih $5 \mathrm{~cm}$ dengan tinggi 5$15 \mathrm{~cm}$ ).

2. Sampel $\mathrm{B}=$ Sampel rebung yang diambil dengan volume ukuran sedang (dengan diameter 5-10 cm dengan tinggi $15-20 \mathrm{~cm}$ ).

3. Sampel $\mathrm{C}=$ Sampel rebung yang diambil dengan volume ukur besar (dengan diameter 10-20 $\mathrm{cm}$ dengan tinggi lebih dari $20 \mathrm{~cm}$ )

Setelah pengambilan sampel selesai, dilakukan perlakuan pada sampel rebung yaitu dibersihkan dan dihaluskan kemudian dilakukan pengukuran kadar asam sianida.

\section{b. Pengolahan Sampel}

Sampel kemudian disimpan pada suhu ruang $25{ }^{\circ} \mathrm{C}-30{ }^{\circ} \mathrm{C}$, lalu sampel dikupas, kemudian dibersihkan, dipotong dan dihaluskan menggunakan blender dengan penambahan akuades untuk memudahkan penghalusan dan melarutkan sianida yang terkandung dalam sampel. Setelah halus, sampel kemudian dikeluarkan dari blender kemudian dimasukkan kedalam gelas kimia dan ditutup dengan aluminium foil untuk mencegah autohidrolisisnya sampel kemudian dilakukan pengukuran kadar asam sianida.

\section{c. Persiapan Pengujian Asam Sianida (HCN)}

\section{Pembakuan larutan induk.}

Pipet $50 \mathrm{ml}$ larutan induk sianida, tambahkan 0,25 $\mathrm{ml}$ indikator rhodamin. Titrasi dengan larutan $\mathrm{AgNO}_{3}$ 0,1 $\mathrm{M}$ sampai titik akhir (warna kuning menjadi merah), hitung kadar sianida dalam larutan induk dengan persamaan berikut:

$$
C=\operatorname{axf} \times 5,204 \times 1 / 5
$$

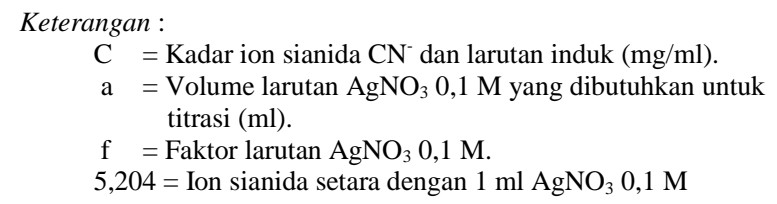

\section{Pembuatan kurva kalibrasi}

Dioptimasikan alat spektrofotometer untuk pengujian kadar asam sianida sesuai petunjuk penggunaan alat pipet 0,$1 ; 0,5 ; 1 ; 2 ; 4 ; 5 ; 7$; dan $9 \mathrm{ml}$ larutan baku sianida $\mathrm{CN}^{-} 1 \mathrm{mg} / \mathrm{l}$ masingmasing kedalam labu ukur $50 \mathrm{ml}$. Tambahkan air suling sehingga volume menjadi kurang lebih 10 ml. Ditambahkan 1 tetes indikator fenolftalein dan netralkan dengan asam asetat sampai warna merah menghilang. tambahkan kurang lebih 10 $\mathrm{ml}$ larutan buffer fosfat $\mathrm{pH} 7,2$. Ditambahkan 0,5 $\mathrm{ml}$ larutan kloramin-T dan dibiarkan pada suhu ruang $25{ }^{\circ} \mathrm{C}-30{ }^{\circ} \mathrm{C}$ selama 5 menit. Ditambahkan $10 \mathrm{ml}$ larutan 4-piridin asam karboksilat-pirazolon lalu tepatkan dengan akuades, ditutup, dikocok dan dibiarkan pada 
suhu ruang kurang lebih 30 menit. Setelah ditepatkan, kadar sianida $\mathrm{CN}^{-}$dalam larutan adalah 0,$01 ; 0,02 ; 0,04 ; 0,08 ; 0,10 ; 0,14$; dan $0,18 \mathrm{mg} / \mathrm{l}$. buat kurva kalibrasi dengan membaca dan mencatat absorbansi masuknya pada panjang gelombang optimal disekitar $582 \mathrm{~nm}$.

\section{Destilasi sampel}

Ditimbang 50 gr sampel yang telah dihaluskan dan masukkankedalam labu didih, tambahkan akuades hingga volume kurang lebih $200 \mathrm{ml}$, tambahkan 3 tetes larutan indikator fenolftalein $0,5 \%$, lalu ditambahkan ammonium amidosulfat $10 \%$ sebanyak $1 \mathrm{ml}$ sampai larutan bersifat asam dan larutan berwarna merah. Ditambahkan lagi dengan asam phophat $10 \mathrm{ml}$ ditambahkan larutan EDTA $10 \mathrm{ml}$, pasang alat destilasi dan alat penampung destilat pada Erlenmeyer yang berisi $20 \mathrm{ml}$ larutan $\mathrm{NaOH} 2 \%$. Bilas injection funnel dengan akuades. Alat destilasi dipanaskandan kecepatan destilasi sekitar 2-3 ml/menit. Destilat ditampung sampai kurang lebih $100 \mathrm{ml}$ dan dibilas pendingin dengan akuades.

\section{Pengujian asam sianida (HCN)}

Dinetralkan hasil destilat dengan $\mathrm{HCl}$ 1:1 sampai bersifat asam. Kemudian sampel dipipet 1 mlmasukkan kedalam labu ukur $100 \mathrm{ml}$ yang telah dicukupkan dengan akuades sampai tanda tera. Lalu sampel yang telah dicukupkan dengan akuades dipipet sebanyak $20 \mathrm{ml}$ dan dimasukkan kedalam gelas ukur lalu ditambahkan dengan $4 \mathrm{ml}$ larutan $\mathrm{NaH}_{2} \mathrm{PO}_{4}$ lalu ditambahkan lagi dengan kloramin $\mathrm{T}$ sebanyak $2 \mathrm{ml}$ dan terakhir ditambahkan lagi dengan asam Barbipurat sebanyak $5 \mathrm{ml}$, lalu dikocok sampai berubah warna menjadi ungu keping pingan jika positif sianida, dimasukkan kedalam kuvet pada spektrofotometer, ukur dan catat absorbannya dengan panjang gelombang $582 \mathrm{~nm}$. Selanjutnya dilakukan pengukuran yang sama pada blanko.

\section{Perhitungan Kadar Sianida}

Dimasukkan hasil pembacaan absorbansi larutan blanko ke dalam kurva kalibrasi. Masukkan hasil pembacaan absorbansi larutan sampel kedalam kurva kalibrasi. Kadar sianida yang sesungguhnya adalah:

Keterangan :

$$
\mathrm{CN}(\mathrm{mg} / \mathrm{Kg})=\frac{a \times b}{c} \mathrm{x} \mathrm{fp}
$$

$a=$ konsentrasi sampel dari alat spektrofotometer

$b=$ sampel uji yang di destilasi $(100 \mathrm{ml})$ dijadikan ke liter

$c=$ berat sampel yang ditimbang dari gr dijadikan $\mathrm{Kg}$.

$d=$ faktor pengenceran

\section{HASIL DAN PEMBAHASAN}

Hasil pemeriksaan kadar sianida diperoleh dalam bentuk $\mathrm{mg} / \mathrm{Kg}$ kemudian hasilnya sesuai dengan penelitian tentang kadar sianida yang tidak berbahaya $<50 \mathrm{mg} / \mathrm{Kg}$ rebung dan berbahaya $>100 \mathrm{mg} / \mathrm{Kg}$ rebung (Julistiana, 2009). Kandungan kadar sianida pada rebung berdasarkan volume ukuran dapat dilihat pada Tabel 1.

Tabel 1 Hasil pemeriksaan analisis kadar sianida pada rebung berdasarkan volume ukuran yang berada di Kecamatan Bajeng Kabupaten Gowa.

\begin{tabular}{llclc}
\hline No. & Sampel & Ukuran & Satuan & $\begin{array}{c}\text { Kadar } \\
\text { sianida }\end{array}$ \\
\hline 1. & Rebung & $\mathrm{d}: 10-20 \mathrm{~cm}$ & $\mathrm{mg} / \mathrm{Kg}$ & 21,84 \\
& Besar & $\mathrm{t}: \geq 20 \mathrm{~cm}$ & & \\
\hline 2. & Rebung & $\mathrm{d}: 5-10 \mathrm{~cm}$ & $\mathrm{mg} / \mathrm{Kg}$ & 18,40 \\
& sedang & $\mathrm{t}: 15-20 \mathrm{~cm}$ & & \\
\hline 3. & Rebung & $\mathrm{d}: \leq 5 \mathrm{~cm}$ & $\mathrm{mg} / \mathrm{Kg}$ & 4,65 \\
& kecil & $\mathrm{t}: 5-15 \mathrm{~cm}$ & & \\
\hline
\end{tabular}

Rebung berdasarkan varietas ukuran ini diambil didaerah Kecamatan Bajeng Kabupaten Gowa. Sebelum dilakukan pemeriksaan rebung tersebut dikupas kulitnya dan dibersihkan namun tidak dibilas dengan menggunakan air karena sianida yang terkandung didalam rebung sangat mudah larut didalam air. Rebung di potong dadudadu agar sianida yang terkandung didalam rebung tidak mudah menguap, lalu di blender agar mempermudah pemeriksaan.

Lalu dilakukan proses destilasi guna untuk pemisahan bahan kimia berdasarkan perbedaan kecepatan atau kemudahan menguap (volatilitas) bahan atau teknik pemisahan kimia berdasarkan perbedaan titik didih. Dalam penyulingan, campuran zat dididihkan sehingga menguap dan uap ini kemudian didinginkan kembali kedalam bentuk cairan. 


\section{Dewi Arisanti dkk. / Indo. J. Chem. Res, 2018, 6(1), 6-11}

Pada proses destilasi ini penambahan ammonium amidosulfat berfungsi untuk mengikat kation-kation yang ada pada sampel dan sifatnya sangat larut didalam air. Penambahan larutan EDTA 10\% berfungsi untuk pemisahan logam-logam yang lantanida melalui kromatorgrafi penukaran ion. Penambahan larutan $\mathrm{NaOH} 2 \%$ yaitu sebagai larutan baku yang bersifat basa yang berfungsi untuk membentuk larutan alkalis yang kuat, sangat mudah larut didalam air, sifatnya lembab, cair dan secara spontan menyerap karbondioksida dari udara bebas dan penambahan indikator phenolftalein atau disebut indikator PP digunakan dalam titrasi asam-basa dan mempermudah reaksi dalam proses perubahan warna.

Sebelum pengujian sianida hasil destilasi sampel rebung harus bersifat asam dengan penambahan larutan $\mathrm{HCl}$ yang berfungsi untuk mengatur keasaman yang telah ditetapkan dalam pengukuran spekrofotometer. Penambahan dapar posphat berfungsi untuk mengatur $\mathrm{pH} . \mathrm{pH}$ asam $<7$ dan $\mathrm{pH}$ basa $>7$, larutan agar tetap konstan di area mendekati $\mathrm{pH}$ 7. Penambahan larutan kloramin $\mathrm{T}$ berfungsi untuk menghasilkan sianogen klorida $(\mathrm{CNCl}) \quad \mathrm{pH}$ kloramin $\mathrm{T}$ akan bereaksi pada $\mathrm{pH} \leq 8$ dan penambahan asam barbiturat untuk memberikan intensitas warna ungu yang berbanding lurus dengan kadar sianida pada sampel.

Pembacaan sianida menggunakan alat spektrofotometer UV-Vis dengan panjang gelombang $582 \mathrm{~nm}$. Karena panjang gelombang maksimumpada pengujian sianida yaitu $582 \mathrm{~nm}$. Oleh karena itu panjang gelombang ini yang digunakan dan panjang gelombang pada parameter pemeriksaan berbeda-beda tergantung dari jenis pemeriksaannya. Pada penelitian ini pada saat pembacaan kadar sianida pada alat ditemukan nilai yang melebihi dari standar maka sampel rebung tersebut dilakukan pengenceran agar nilai absorban yang didapatkan sesuai dengan standar kalibrasi pada alat.

Berdasarkan volume ukuran diperoleh hasil dalam bentuk kadar sianida pada rebung yakni sampel rebung dengan ukuran besar dengan tinggi $27 \mathrm{~cm}$ dengan diameter $16 \mathrm{~cm}$ dengan kadar $21,84 \mathrm{mg} / \mathrm{Kg}$, sampel rebung dengan ukuran sedang dengan tinggi $18 \mathrm{~cm}$ dengan diameter $7 \mathrm{~cm}$ dengan kadar $18,40 \mathrm{mg} / \mathrm{Kg}$ dan rebung dengan ukuran kecil dengan tinggi $8 \mathrm{~cm}$ dengan diameter $4 \mathrm{~cm}$ dengan kadar $4,65 \mathrm{mg} / \mathrm{Kg}$. Perbedaan kadar pada rebung dapat dilihat pada diagram batang dibawah ini yang menunjukkan bahwa kadar sianida lebih tinggi pada rebung besar dibandingkan rebung sedang dan rebung kecil.

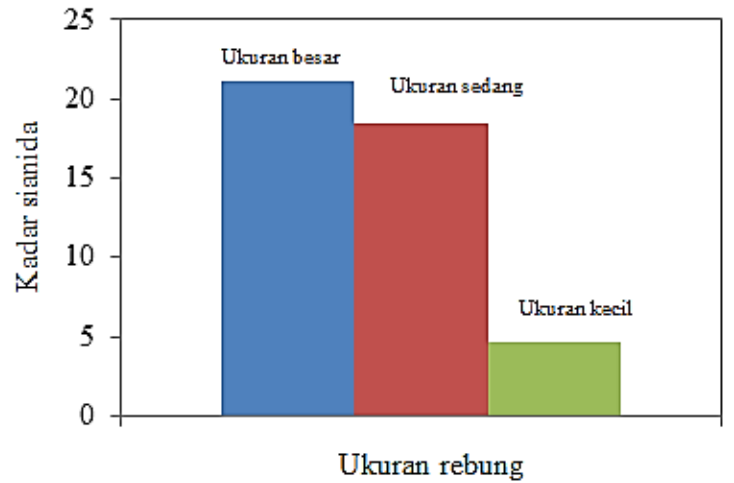

Gambar 1. Grafik kenaikan sianida berdasarkan volume ukuran

Faktor yang mempengaruhi terdapat perbedaan kadar sianida berdasarkan volume ukuran karena adanya getah yang berwarna putih secara alami disetiap tunas rebung tersebut. Dimana getah putih itu mengandung zat glukosida sianogenik. Semakin besar rebung maka getah yang dihasilkan juga semakin banyak. Rasa rebung juga semakin pahit yang menandakan kandungan sianidanya juga semakin banyak. Begitupula sebaliknya jika semakin kecil rebung getah putih yang dihasilkan juga sedikit sehingga kadar sianida dalam rebung tersebut juga sedikit.

Hubungan dari zat glikosida sianogenik dengan sianida yaitu dimana kita ketahui bahwa glikosida sianogenik adalah senyawa hidrokarbon yang terikat dengan gugus $\mathrm{CN}$ dan gula. Beberapa tanaman tingkat tinggi dapat melakukan sianogenesis yakni membentuk glikosida sianogen sebagai hasil sampingan reaksi biokimia dalam tanaman. Glikosida 


\section{Dewi Arisanti dkk. / Indo. J. Chem. Res, 2018, 6(1), 6-11}

sianogenik ini terdapat pada tanaman singkong, almond, bambu, shorgum.

Tahap pelepasan asam sianida, glikosida sianogenik dapat terhidrolisis secara enzimatis menghasilkan asam sianida (HCN). Hidrolisis ini dilakukan oleh enzim beta glikosida. Menghasilkan gula dan sianohidrin. Degradasi sianohidrin menjadi $\mathrm{HCN}$ dan senyawa keton aldehid. Asam sianida dilepaskan oleh glikosida sianogenik merupakan senyawa toksik berspektrum luas pada setiap organisme hal ini disebabkan karena kemampuannya mengikat $\mathrm{Fe}^{2+}, \mathrm{Mn}^{2+}$ dan $\mathrm{CU}^{2+}$ (Smith dan Mudder 1991).

Racun alami pada rebung yaitu glikosida sianogenik dimana gejala keracunannya mirip dengan gejala keracunan pada singkong. Jika kadar sianida masuk kedalam tubuh dengan jumlah kecil maka akan berikatan dengan vitamin B12 sehingga dapat di ekresikan melalui urine. Namun jika kadar sianida masuk kedalam tubuh dalam jumlah yang banyak maka akan berikatan dengan tiosianat yang menyerang bagian enzim oksidase sehingga dapat menghentikan metabolisme secara aerobik.

Cara untuk mengurangi kadar sianida pada rebung yaitu dengan cara dibersihkan dengan menggunakan air yang mengalir, dilakukan perendaman pada air garam, dimasak dengan menggunakan air yang mendidih dan jika dimasak usahakan tutup wajan dibuka agar sianida menguap.

Berdasarkan data pengamatan uji kuantitatif pada sampel rebung berdasarkan volume ukuran kadar yang didapatkan tidak melebihi ambang batas karena kadar yang diperoleh kurang dari 50 $\mathrm{mg} / \mathrm{Kg}$ rebung (Juliastina, 2009).

Pada hasil penelitian ini kadar sianida tertinggi masih layak untuk dikonsumsi karena hasil yang diperoleh yaitu kurang dari $50 \mathrm{mg} / \mathrm{Kg}$ HCN. Hal ini menunjukkan bahwa rebung dapat dikonsumsi namun, jangan keseringan dan alangkah baiknya pilih rebung yang masih muda dan ukurannya yang lebih kecil.

Menurut FAO, untuk rebung yang dikonsumsi kandungan asam sianida maksimal yang diperbolehkan dikonsumsi yaitu kurang dari $50 \mathrm{mg} / \mathrm{Kg}$ oleh karena itu, dalam penggunaan rebung sebagai bahan pangan perlu dilakukan perlakuan-perlakuan khusus untuk menurunkan kandungan kadar sianida. Prinsip pengujian pada pemeriksaan sianida pada rebung yaitu larutan yang mengandung ion sianida $(\mathrm{CN})$ dalam destilat dinetralkan dengan asam phosphat. Ion sianida $(\mathrm{CN})$ bereaksi dengan kloramin $\mathrm{T}$ menghasilkan $\mathrm{CNCl}$ ini kemudian bereaksi dengan asam barbiturat menghasilkan senyawa yang berwarna ungu, warna ungu ini kemudian diukur absorbansinya pada panjang gelombang $582 \mathrm{~nm}$.

\section{KESIMPULAN}

Berdasarkan hasil penelitian analisis kadar sianida pada 3 sampel rebung yang dianalisis kadar masing-masing sampel yaitu sampel rebung dengan ukuran besar dengan tinggi $27 \mathrm{~cm}$ dengan diameter $16 \mathrm{~cm}$ dengan kadar 21,84 $\mathrm{mg} / \mathrm{Kg}$, sampel rebung dengan ukuran sedang dengan tinggi $18 \mathrm{~cm}$ dengan diameter $7 \mathrm{~cm}$ dengan kadar 18,40 mg/Kg dan Rebung dengan ukuran kecil dengan tinggi $8 \mathrm{~cm}$ dengan diameter $4 \mathrm{~cm}$ dengan kadar $4,65 \mathrm{mg} / \mathrm{Kg}$. perbedaan kadar sianida yang menunjukkan kadar sinida lebih tinggi pada rebung ukuran besar dibandingkan ukuran sedang dan kecil. Namun, kadar sianida pada sampel ketiga tidak melebihi ambang batas yang diizinkan yaitu sebesar $50 \mathrm{mg} / \mathrm{Kg} \mathrm{HCN}$ rebung.

\section{DAFTAR PUSTAKA}

Bradbury, J.H.dan W.D Holloway, 1988, Chemistry of Tropical Root Crops: significance for nutrition and Agriculture in the pacific. Australian centre of International Agricultural Research, Canberra.

Fsanz, 2005, Rebung kaya serat penangkal stroke, diakses tanggal 27 Agustus 2010.

Julistiana, Ra Etika, 2009, Pengembangan dan validasi metode pengujian kadar sianida dalam limbah cair secara spektroskopi UVVis., Skripsi, Departemen Kimia Fakultas Matematika dan Ilmu Pengetahuan Alam Institut Pertanian Bogor.

Kencana P.K., Diah, 2009, Fisiologi dan Teknologi Pascapanen Rebung Bambu 
Dewi Arisanti dkk. / Indo. J. Chem. Res, 2018, 6(1), 6-11

Tabah (Gigantohloa nigrociliata kuiz), Disertasi program pascasarjana Fakultas Pertanian Universitas Branisya Malang.

Kencana, P.K.D,B.S Widia W.N.S Antara, 2012, praktek baik Budidaya Daya Bambu Rebung Bambu Tabah (Gigantochloa nigrociliataBuze-Kuiz), Team UNUDUNSAD-TPC Prpject.
Smith, A and Mudder, T., 1991, The Chemistry and Treatment of Cyanidation Waste, Mining Journal Books Ltd., London.

Yuningsih, 2008, Kandungan dan Stabilitas Sianida Dalam Tanaman Picung (Pangium edule Reinw) Serta Pemanfaatannya. Balai Besar Penelitian Veteriner, hal. 102-109. 